\title{
Chemical Vapor Deposition of Hollow Graphitic Spheres for Improved Electrochemical
} Durability

Knossalla, J.; Mielby, J.; Göhl, D.; Wang, F. R.; Jalalpoor, D.; Hopf, A.; Mayrhofer, K. J.J.; Ledendecker, M.; Schüth, F.

\section{Published in:}

ACS Applied Energy Materials

Link to article, DOI:

10.1021/acsaem.1c00643

Publication date:

2021

Document Version

Publisher's PDF, also known as Version of record

Link back to DTU Orbit

Citation $(A P A)$ :

Knossalla, J., Mielby, J., Göhl, D., Wang, F. R., Jalalpoor, D., Hopf, A., Mayrhofer, K. J. J., Ledendecker, M., \& Schüth, F. (2021). Chemical Vapor Deposition of Hollow Graphitic Spheres for Improved Electrochemical Durability. ACS Applied Energy Materials, 4(6), 5840-5847. https://doi.org/10.1021/acsaem.1c00643

\section{General rights}

Copyright and moral rights for the publications made accessible in the public portal are retained by the authors and/or other copyright owners and it is a condition of accessing publications that users recognise and abide by the legal requirements associated with these rights.

- Users may download and print one copy of any publication from the public portal for the purpose of private study or research.

- You may not further distribute the material or use it for any profit-making activity or commercial gain

- You may freely distribute the URL identifying the publication in the public portal 


\title{
Chemical Vapor Deposition of Hollow Graphitic Spheres for Improved Electrochemical Durability
}

\author{
J. Knossalla, J. Mielby, D. Göhl, F. R. Wang, D. Jalalpoor, A. Hopf, K. J. J. Mayrhofer, M. Ledendecker, \\ and F. Schüth*
}

Cite This: ACS Appl. Energy Mater. 2021, 4, 5840-5847

Read Online

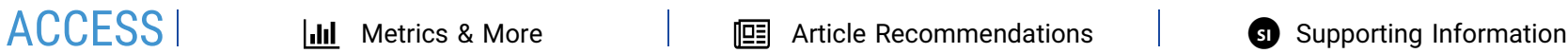

ABSTRACT: The wet-chemical synthesis of hollow graphitic spheres, a highly defined model catalyst support for electrocatalytic processes, is laborious and not scalable, which hampers potential applications. Here, we present insights into the chemical vapor deposition (CVD) of ferrocene as a simple, scalable method to synthesize hollow graphitic spheres $\left(\mathrm{HGS}_{\mathrm{cvd}}\right)$. During the CVD process, iron and carbon are embedded in the pores of a mesoporous silica template. In a subsequent annealing step, iron facilitates the synthesis of highly ordered graphite structures. We found that the applied temperature treatment allows for controlling of the degree of graphitization and the textural properties of $\mathrm{HGS}_{\mathrm{cvd}}$. Further, we demonstrate that platinum loaded on $\mathrm{HGS}_{\mathrm{cvd}}$ is significantly more stable during electrochemical degradation

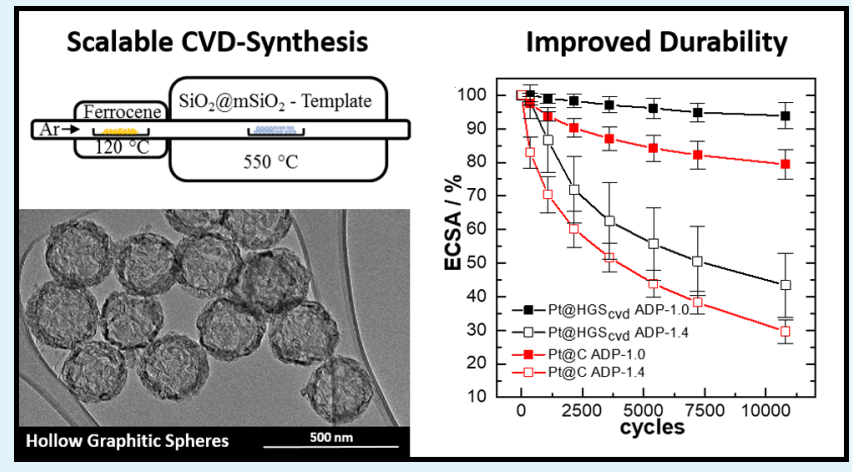
protocols than catalysts based on commercial high surface area carbons. The established CVD process allows the scalable synthesis of highly defined HGS and therefore removes one obstacle for a broader application.

KEYWORDS: mesoporous carbon, liquid-free synthesis, chemical vapor deposition, stability enhancement, PEMFC

\section{INTRODUCTION}

Increasing energy demand and depletion of fossil resources lead to an intensified search for alternative and sustainable energy systems. One promising technology for mobile applications is the polymer electrolyte membrane fuel cell. ${ }^{1,2}$ The electrical energy is generated from the electrochemical reaction between hydrogen and oxygen, with water as the only byproduct. Typical state-of-the-art catalysts for the oxygen reduction reaction (ORR) on the cathode side of the fuel cell consist of homogeneously dispersed platinum and platinumalloy nanoparticles supported on high surface area carbon materials. ${ }^{3}$ A major restriction in successful commercialization and implementation of the technology is the availability of platinum and its high overpotential as well as the lack of longterm stability. ${ }^{4-6}$ The underlying degradation mechanisms were identified by means of identical location transmission electron microscopy (TEM). ${ }^{7,8}$ In general, the degradation can be divided into five mechanisms, including Pt dissolution, Ostwald ripening, carbon corrosion, particle detachment, and agglomeration. $^{9-11}$ Hollow graphitic spheres (HGS) were reported to significantly suppress degradation mechanisms such as particle detachment and agglomeration, thanks to a confinement of the nanoparticles in the mesopores of the HGS. ${ }^{10-12}$ Templating methods are typically utilized for the synthesis of mesoporous materials with tailored textural properties, subdivided into hard and soft templating methods. ${ }^{13,14}$ The wet-chemical synthesis of HGS requires a multi-step hard templating process: initially, core-shell mesoporous silica spheres $\left(\mathrm{SiO}_{2} @ \mathrm{mSiO}_{2}\right)$ are synthesized, as reported by Büchel et al. ${ }^{15}$ These hard templates are employed to scaffold the textural properties (i.e., shell thickness, pore size, and void diameter) of the resulting HGS replica. For this, divinylbenzene, as the carbon source, and iron, as the graphitization catalyst, are infiltrated in three subsequent impregnation steps. ${ }^{10,12}$ Overall, this complex multistep procedure, partly at high dilution, makes scale-up of the synthesis process very difficult, thus hampering the technical use of fuel cell catalysts based on this process. ${ }^{16-19}$

Alternatively, replication of nanostructured templates could be achieved via chemical vapor deposition (CVD) processes. ${ }^{20}$ Classically, CVD is used for the production of solid thin films on flat substrates, and also mesoporous membranes were employed as templates for the synthesis of carbon nanotubes. $^{21-24}$ Commonly, gaseous hydrocarbons (e.g., ethylene, methane, benzene, and acetylene) are decomposed at the host

Received: March 4, 2021

Accepted: June 2, 2021

Published: June 11, 2021 
material. $^{25-28}$ The simultaneous deposition of metal particles and carbon was achieved by sublimation and subsequent pyrolysis of ferrocene. ${ }^{29}$ Recently, Lei et al. ${ }^{30}$ extended this approach, employing mesoporous ordered silica (SBA-15) powder as the template. The strong interaction of the pyrolytic carbon clusters with the pore walls of the SBA-15 led to the formation of ordered mesoporous carbon (CMK-5) replicas. In contrast to the wet-chemical impregnation process, the incorporation of iron and carbon was obtained within a single step. The embedded iron can be utilized to catalyze the graphitization of the decomposed carbon, ${ }^{31,32}$ significantly altering the textural properties of the obtained carbon replica. ${ }^{30}$ Additionally, the CVD of ferrocene employing $\mathrm{SiO}_{2} @ \mathrm{mSiO}_{2}$ templates was reported for the synthesis of hollow graphitic carbon spheres. ${ }^{33-36}$

In the following, the influence of temperature on the graphitization degree and the consequential textural changes of the resulting hollow graphitic spheres $\left(\mathrm{HGS}_{\mathrm{cvd}}\right)$ are reported in detail. Additionally, the $\mathrm{HGS}_{\mathrm{cvd}}$ supports were decorated with Pt nanoparticles and employed for the ORR demonstrating improved catalytic durability compared to Pt nanoparticles loaded on commercial high surface area carbon ( $\mathrm{Pt} @ \mathrm{C})$.

\section{EXPERIMENTAL SECTION}

HGS $_{\text {cvd }}$ Synthesis. The synthesis of the hard template was reported by Büchel et al. ${ }^{15} \mathrm{~A}$ detailed report on the wet-chemical synthesis of HGS, including the hard template, was compiled by our group. ${ }^{16}$ Briefly, $350 \mathrm{~mL}$ of ethanol, $65 \mathrm{~mL}$ of water, and $7.6 \mathrm{~mL}$ of ammonium hydroxide solution ( $25 \mathrm{wt} \%$ in water) were mixed for 5 min. Then, $13.9 \mathrm{~mL}$ of TEOS was added under rapid stirring. After 2 h, a mixture of $9.9 \mathrm{~mL}$ of TEOS and $3.9 \mathrm{~mL}$ of OTMS was added to the white suspension. The mixture was stirred overnight. Then, the suspension was centrifuged and the solid was dried at $75{ }^{\circ} \mathrm{C}$ overnight. The dried material was calcined in air with a heating rate of $1 \mathrm{~K} / \mathrm{min}$ to a final temperature of $550^{\circ} \mathrm{C}$. The dwelling time was $3 \mathrm{~h}$. The obtained solid was ground using a mortar and pestle.

For the CVD of ferrocene, the procedure described by Lei et al. was adapted. ${ }^{34}$ Typically, a quartz crucible containing $2 \mathrm{~g}$ of $\mathrm{SiO}_{2} @ \mathrm{mSiO}_{2}$ template and a crucible containing $10 \mathrm{~g}$ of ferrocene were placed in a quartz tube. The quartz tube was transferred into a tubular furnace that was heated to $550^{\circ} \mathrm{C}$ for $1.5 \mathrm{~h}(5 \mathrm{~K} / \mathrm{min})$ in an argon flow of 100 $\mathrm{mL} / \mathrm{min}$, with the crucible containing the template centered in the heating zone. The quartz tube inlet was enveloped with a heating jacket that was rapidly heated to $120{ }^{\circ} \mathrm{C}$ (standard tube, NS29) or $140{ }^{\circ} \mathrm{C}$ (large setup, NS45) once the tubular furnace reaches $500{ }^{\circ} \mathrm{C}$. The crucible containing ferrocene was centered to the heating zone of the heating jacket. After a dwelling time of $1.5 \mathrm{~h}$, both heating devices were switched off and cooled to ambient temperature naturally while maintaining the Ar flow. The resulting composite material spontaneously ignites in the presence of air, presumably caused by the finely dispersed iron nanoparticles in the material. Therefore, the sample was passivated by the aid of an $\mathrm{O}_{2} / \mathrm{N}_{2}(1: 99 \mathrm{vol} \%)$ flowing gas mixture of $100 \mathrm{~mL} / \mathrm{min}$ for $>1.5 \mathrm{~h}$ before it can be safely stored without further precautionary measure. Following the passivation, the sample was heated in $90 \mathrm{~min}$ to the respective annealing temperature of $1000{ }^{\circ} \mathrm{C}, 900{ }^{\circ} \mathrm{C}, 800{ }^{\circ} \mathrm{C}$, or $700{ }^{\circ} \mathrm{C}$ for $4 \mathrm{~h}$ in an argon flow of 100 $\mathrm{mL} / \mathrm{min}$. The silica residues were leached by HF: $1 \mathrm{~g}$ of composite was submerged in $7 \mathrm{~mL}$ of $\mathrm{HF}$ (40\%) for $24 \mathrm{~h}$ and washed with water multiple times. Following the silica leaching, leaching of iron was performed by the addition of an excess of $7 \mathrm{~mL} / \mathrm{g}_{\text {composite }} \mathrm{HCl}(30 \%)$ overnight. Finally, the samples were washed with water and dried at $80{ }^{\circ} \mathrm{C}$ overnight.

Pt@HGS cvd Synthesis. The synthesis of Pt@HGS can be subdivided into three individual steps. Initially, the metal precursors are impregnated via incipient wetness impregnation. For a typical synthesis of $100 \mathrm{mg} \mathrm{Pt} @ \mathrm{HGS}_{\mathrm{cvd}}, 80 \mathrm{mg}$ of the $\mathrm{HGS}_{\mathrm{cvd}}$ support was impregnated with $\mathrm{H}_{2} \mathrm{PtCl}_{6} \times x \mathrm{H}_{2} \mathrm{O}_{\mathrm{aq}} . \mathrm{H}_{2} \mathrm{PtCl}_{6} \times x \mathrm{H}_{2} \mathrm{O}_{\mathrm{aq}}(38.8 \mu \mathrm{L}$,
$2.64 \mathrm{~mol} / \mathrm{L}$; $\geq 99.9 \%$; Sigma-Aldrich) was dissolved in $10.9 \mu \mathrm{L}$ of Millipore water $\left(18.2 \mathrm{M} \Omega \mathrm{cm}\right.$ at $\left.25{ }^{\circ} \mathrm{C}\right)$. The resulting solution is equal to the total pore volume of the employed support. In order to ensure complete pore filling, the powder was sonicated for $30 \mathrm{~min}$. For the second step, the powder was dried and subsequently reduced. Therefore, the sample was dried for $60 \mathrm{~min}$ at $120^{\circ} \mathrm{C}(3 \mathrm{~K} / \mathrm{min})$ under an Ar flow (300 mL/min) and subsequently heated to $220^{\circ} \mathrm{C}$ $(3 \mathrm{~K} / \mathrm{min})$ under a $\mathrm{H}_{2} / \mathrm{Ar}$ gas stream $(60 / 240 \mathrm{~mL} / \mathrm{min})$ with a holding time of $90 \mathrm{~min}$. The sample was cooled naturally to ambient temperature under an $\mathrm{Ar}$ flow $(300 \mathrm{~mL} / \mathrm{min})$. Finally, the sample was annealed at $850{ }^{\circ} \mathrm{C}$ for $2.5 \mathrm{~h}(5 \mathrm{~K} / \mathrm{min})$ under an $\mathrm{Ar}$ atmosphere (200 $\mathrm{mL} / \mathrm{min}$ ).

X-ray Diffraction Analysis. A Bragg Brentano diffractometer $(\Theta /$ $\Theta)$ from STOE ( $\mathrm{Cu} \mathrm{K} \alpha 1,2 \mathrm{X}$-ray source), equipped with a secondary graphite monochromator and a proportional gas detector, was employed for the collection of the X-ray diffraction (XRD) pattern. The opening of the divergence slit was set to $0.8^{\circ}$ and the receiving slit was set to $0.6 \mathrm{~mm}$. The width of the horizontal mask was chosen to be $8 \mathrm{~mm}$. A background-free single-crystal quartz sample holder was employed for the measurements.

$\mathrm{N}_{2}$ Physisorption. The measurements were carried out with a Micromeritics 3 Flex instrument. The samples were activated under vacuum for at least $8 \mathrm{~h}$ at $250{ }^{\circ} \mathrm{C}$. The measurements were performed at $77.4 \mathrm{~K}$ using a static volumetric method with a relative pressure tolerance of $5 \%$. For relative pressures below $0.1 p / p^{0}$, an incremental dose mode $\left(15 \mathrm{~cm}^{3} / \mathrm{g}\right.$ STP, equilibration intervals $\left.10 \mathrm{~s}\right)$ was employed.

Transmission Electron Microscopy. The TEM micrographs were obtained using a Hitachi H-7100 microscope (100 kV, Wcathode) and a Hitachi HF-2000 microscope $(200 \mathrm{kV})$ equipped with a cold field emission gun. All samples were placed on a Lacey carbon film supported by a copper grid without further treatment.

Thermogravimetric Analysis. Thermogravimetric analysis (TGA) and differential scanning calorimetry (DSC) were performed on a Netzsch STA 449F3 thermal analyzer. The measurements were performed in the temperature range of $45-1000{ }^{\circ} \mathrm{C}$ conducted with a heating rate of $20 \mathrm{~K} / \mathrm{min}$. The gas composition was set to $60 / 40 \mathrm{~mL} /$ $\min$ (air/Ar), where argon is employed as a protective purge.

Half-Cell Electrochemical Measurements. The specific activity (SA), mass activity (MA), and electrochemical surface area (ECSA) were measured via a thin-film rotating disk electrode (RDE) method. The electrochemical measurements were performed in a threeelectrode compartment Teflon cell at room temperature. The catalyst ink consisted of a catalyst powder dispersed in $5 \mathrm{~mL}$ of ultrapure water with an ultrasound bath; a $20 \mu \mathrm{L}$ droplet of the suspension was then deposited onto a carbon disk of $0.196 \mathrm{~cm}^{2}$ geometric surface area, embedded in a Teflon tip. A catalyst loading of $10 \mu \mathrm{g}_{\mathrm{pt}} / \mathrm{cm}^{2}$ was employed for stability and activity investigations. For the degradation tests, a droplet of Nafion ( $7 \mu \mathrm{L}$ of a 5 wt \% Nafion/isopropanol solution $1 / 50$ ) was deposited onto the dry catalyst film. The Teflon tip was then connected to a RDE (Radiometer Analytical, France), which served as the working electrode. Both the counter electrode, a graphite rod, and the reference electrode, a saturated $\mathrm{Ag} / \mathrm{AgCl}$ electrode (Metrohm), were housed in separate compartments. In order to avoid chloride contamination, the reference electrode compartment was further separated from the main compartment by a Nafion membrane (Tschurl modification). A Gamry reference 600 potentiostat was employed and controlled in combination with the rotator and the gas system with an in-house-developed LabVIEW software. The electrolyte consisted of $0.1 \mathrm{M} \mathrm{HClO}_{4}$ which was prepared with ultrapure water $(18 \mathrm{M} \Omega \mathrm{cm}$, Millipore) and concentrated $\mathrm{HClO}_{4}$ (Merck, Suprapur). The Ohmic drop was compensated by positive feedback. All potentials are given with respect to the reversible hydrogen electrode (RHE) potential, which was determined for each experiment individually. Activities were extracted from cyclic voltammograms $(\mathrm{CVs})$ recorded in an $\mathrm{O}_{2}-$ saturated electrolyte at $1600 \mathrm{rpm}$ and at $0.9 \mathrm{~V}_{\mathrm{RHE}}$ with a $50 \mathrm{mV} / \mathrm{s} \mathrm{scan}$ rate. In order to isolate the contribution related to oxygen reduction, the $\mathrm{RDE}$ polarization curves were corrected for capacitive processes ( $\mathrm{CV}$ in an Ar-saturated electrolyte). 
The accelerated degradation tests include two specific protocols, namely, ADP-1.0 and ADP-1.4, which consisted of 10,800 degradation cycles at $1 \mathrm{~V} / \mathrm{s}$ between 0.4 and 1.0 and 0.4 and 1.4 $\mathrm{V}_{\mathrm{RHE}}$, respectively. The degradation tests were performed without rotation and in an Ar-saturated electrolyte. In order to monitor the ECSA evolution during degradation, CO-stripping was employed to measure the ECSA after 0, 360, 1080, 2160, 3600, 5400, 7200, and 10,800 potential cycles.

The CO-stripping curves were integrated subtracting the nonfaradic contribution ( $\mathrm{CV}$ in Ar-saturated electrolyte) and assuming a Pt surface charge density of $380 \mu \mathrm{C} / \mathrm{cm}^{2}$. The relative ECSA values were calculated by normalizing the measured ECSA with respect to the ECSA determined after 200 activation cycles. More details about this method can be found in ref 11 . The electrochemical activation procedure applied consisted of 200 cleaning cycles $\left(0.05-1.4 \mathrm{~V}_{\mathrm{RHE}}\right.$ $0.2 \mathrm{~V} / \mathrm{s}$ ). In this phase, the surface carbon impurities are removed. This protocol was applied prior to the determination of SA and ECSA, as well as in the first 200 cycles of the ADP protocol. The commercial catalyst Pt@C used for comparison was purchased from Tanaka and had a platinum loading of $46 \mathrm{wt} \%$ and a mean platinum particle size of $3 \mathrm{~nm} .^{11}$

\section{RESULTS AND DISCUSSION}

The employed setup for the $\mathrm{HGS}_{\mathrm{crd}}$ synthesis is depicted in Figure 1. Both ferrocene and the silica template, placed inside

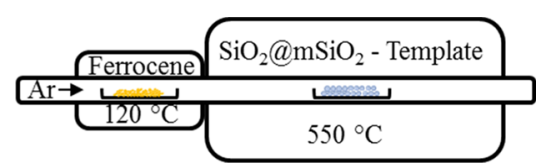

Figure 1. Scheme of the setup for the CVD process.

individual quartz crucibles, are arranged in consecutive heating zones. Ferrocene is heated to $120{ }^{\circ} \mathrm{C}$ and transported by a constant Ar flow over the $\mathrm{SiO}_{2} @ \mathrm{mSiO}_{2}$ silica template, located in the center of a tube furnace heated to $550{ }^{\circ} \mathrm{C}$. Ferrocene decomposes exclusively inside the mesoporous network of the template (Figures S1 and S2) due to the high affinity of ferrocene to the silica template surface. ${ }^{37}$

The composite was annealed at $700,800,900$, and $1000{ }^{\circ} \mathrm{C}$ under an $\mathrm{Ar}$ atmosphere. Following the annealing step, the silica template and iron particles were removed in two distinct acid leaching steps. The final samples were referred to as $\mathrm{HGS}_{\mathrm{cvd}}-700,-800,-900$, and -1000 to indicate their annealing temperature. For all the heat-treated samples, a significant increase in thermal stability was observed compared to the leached composite material (Figure S3).

The graphitization degree after the different annealing steps was analyzed by XRD measurements (Figure 2).

The absence of reflections for the $\mathrm{HGS}_{\mathrm{cvd}}-800$ sample indicates the presence of disordered carbon structures. For $\mathrm{HGS}_{\mathrm{cvd}}-900$ and -1000 , the reflections visible at $26^{\circ}(002)$ and $42^{\circ}$ (100) reveal the presence of additional highly ordered graphite structures. The graphitization of carbon is catalyzed by embedded iron nanoparticles from the CVD process. ${ }^{38,39}$ Without iron, temperatures well above $2000 \mathrm{~K}$ would be required to obtain highly ordered graphite structures. ${ }^{31}$ The difference in relative intensity, comparing $\mathrm{HGS}_{\mathrm{cvd}}-900$ and -1000 , corresponds to a difference in the degree of graphitization. Further insights are obtained by TGA and DSC (Figure 3).

The TGA curves show an onset of thermal decomposition at $\sim 500{ }^{\circ} \mathrm{C}$, whereas for $\mathrm{HGS}_{\mathrm{cvd}}-900$ and -1000 , an additional shoulder at around $700{ }^{\circ} \mathrm{C}$ is present. This is in agreement

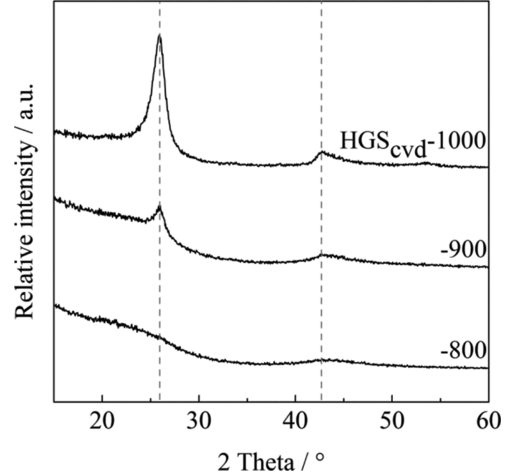

Figure 2. X-ray diffractogram for $\mathrm{HGS}_{\mathrm{cvd}}-1000$, -900 , and -800 . Dashed lines were added as a guideline for the eye, highlighting the reflections attributed to graphite.
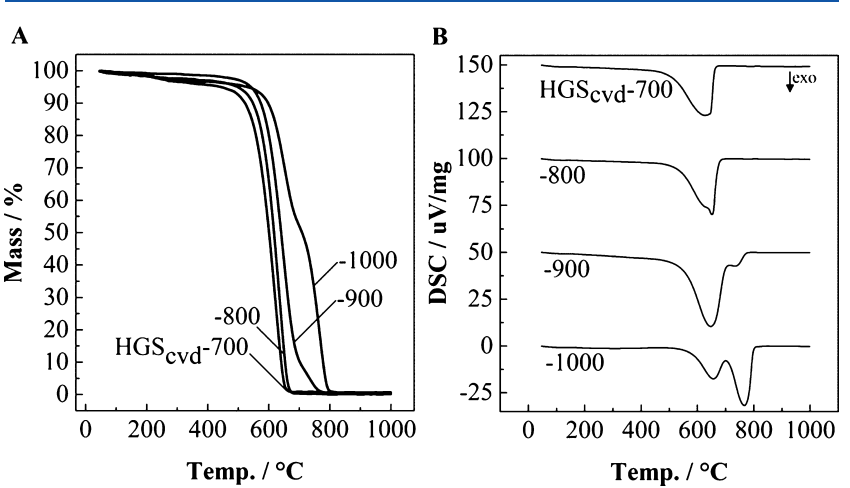

Figure 3. TGA (A) and DSC (B) of HGS ${ }_{\mathrm{cvd}}$ annealed at different temperatures. The DSC data is plotted with a respective $y$-axis offset of $50 \mu \mathrm{V} / \mathrm{mg}$ between traces for clarity.

with the corresponding DSC signals, in which a second peak evolved between 700 and $800{ }^{\circ} \mathrm{C}$ for the $\mathrm{HGS}_{\mathrm{cvd}}-900$ and -1000 samples. These results indicate the presence of two distinct carbon structures, with highly graphitic carbon having higher thermal stability. ${ }^{31}$ This again supports the finding that the higher annealing temperatures lead to the formation of highly ordered carbon structures. Based on the TGA curves, quantification of the distinct carbon structures is possible. HGS $_{\text {cvd }}-900$ and -1000 contain $\sim 8$ and $\sim 48$ wt \% of the highly ordered graphite structure, respectively. Images of the different $\mathrm{HGS}_{\mathrm{cvd}}$ samples obtained by TEM are presented in Figure 4 and in the Supporting Information (Figures S4 and S5). A comparison of the materials by Raman spectroscopy is provided in Figure S6.

The micrographs show successful replication of the $\mathrm{SiO}_{2} @$ $\mathrm{mSiO}_{2}$ templates, presenting a mesoporous shell with a hollow interior. For the HGS-900 and -1000 samples, carbon tube-like structures are present, randomly oriented and enveloping the mesoporous shell. These structures show a high degree of crystallinity, with an interlayer distance of $0.33 \mathrm{~nm}$ determined by TEM. The quantitative difference is in agreement with previous measurements, as their fraction significantly increases with higher annealing temperature. In order to gain further understanding of the formation of the highly ordered graphite structures, the pre-leached composites $\left(\mathrm{HGS}_{\text {composite }}\right)$ are inspected (Figure 5).

The $\mathrm{HGS}_{\text {composite }}-700,-800$, and -900 samples show a homogeneous distribution of iron particles (Figures 5 and S7), with average particle sizes of $10.4 \pm 1.9,11.8 \pm 1.8$, and $15.6 \pm$ 

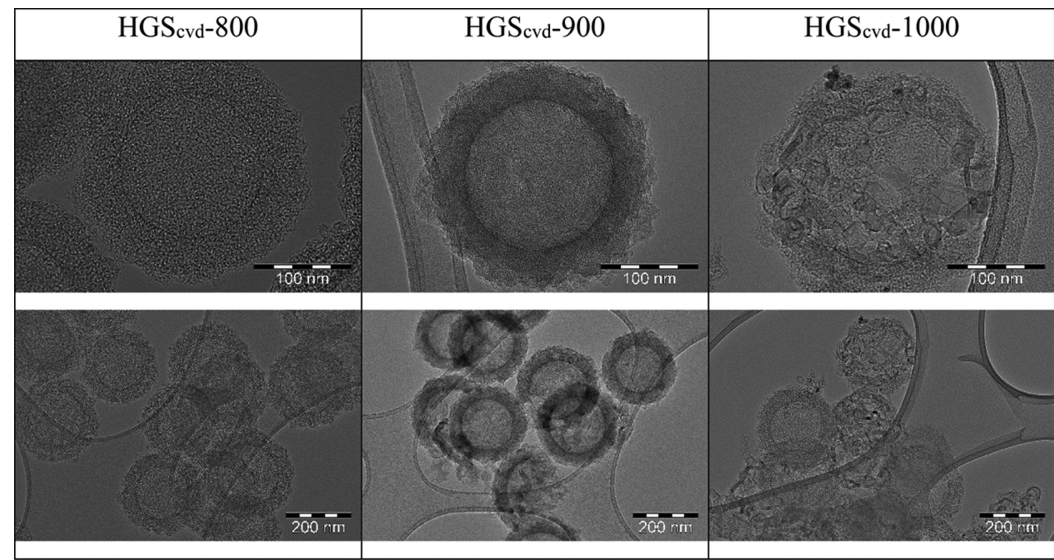

Figure 4. TEM micrographs of the $\mathrm{HGS}_{\mathrm{cvd}}-800$, -900 , and -1000 samples.

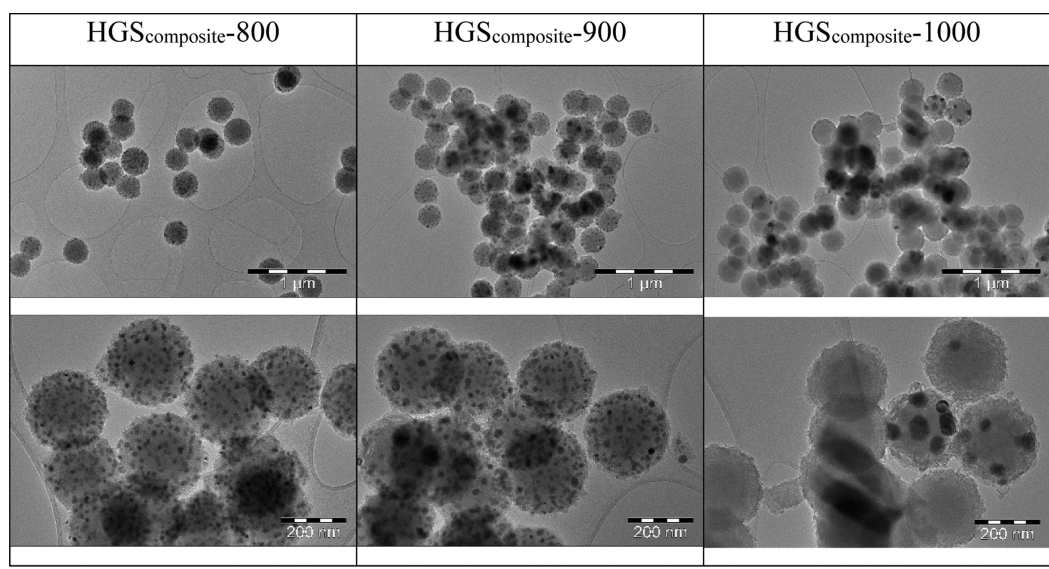

Figure 5. TEM micrographs of the pre-leached composite materials of the $\mathrm{HGS}_{\text {ccomposite }}-800$, -900 , and -1000 samples.

$4.5 \mathrm{~nm}$, respectively. The corresponding increase in particle size can be attributed to the increase in temperature, accelerating particle growth. For $\mathrm{HGS}_{\text {composite }}-1000$, the iron particle size distribution is highly inhomogeneous, with particle diameters exceeding $>50 \mathrm{~nm}$, which are also infrequently found for the HGS composite $^{-900}$ sample. Additionally, the iron particles formed during annealing are unevenly distributed, and in the majority of composite structures, no iron particles can be found. These results suggest that the carbon tube-like growth process presumably causes the formation of highly ordered graphite structures, similar to the nanotube growth observed via in situ TEM studies, ${ }^{38,40}$ ultimately leading to the formation of large iron particle agglomerates.

The influence of the formation of highly ordered graphite on mesoporosity is analyzed by $\mathrm{N}_{2}$ physisorption measurements (Figure 6).

The different $\mathrm{HGS}_{\mathrm{cvd}}$ samples and the silica template show type IV(a) isotherms, ${ }^{41}$ indicating that the templating process is generally successful. For the carbon replicas, a significant increase in surface area and pore volume is obtained due to the lower density of carbon and the absence of a dense core. The $\mathrm{HGS}_{\mathrm{cvd}}-1000$ sample shows a significant decrease in adsorbed quantity compared to $\mathrm{HGS}_{\mathrm{cvd}}-900$ and -800 . This decrease can be attributed to the increased fraction of highly ordered graphite and the partial collapse of the templated mesoporous network. $^{42}$ The iron-catalyzed growth is achieved if the concentration of carbon exceeds its solubility limit in the iron particles. ${ }^{39}$ Thus, the disordered carbon dissolves in the

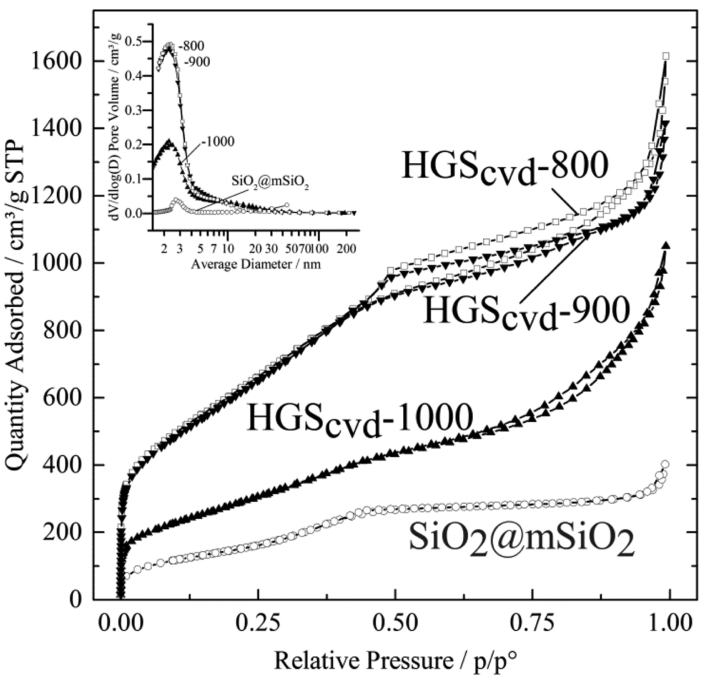

Figure 6. $\mathrm{N}_{2}$ physisorption isotherm of the template material ( $\mathrm{SiO}_{2} @$ $\mathrm{mSiO}_{2}$ ) and $\mathrm{HGS}_{\mathrm{cd}}-1000,-900$, and -800 . The inset shows the pore size distributions determined by the $\mathrm{BJH}$ method from the adsorption branch.

iron particles and precipitates in the form of highly ordered graphite, growing as a tube-like structure through the mesoporous replica. Consequently, a decrease in pore volume and surface area with increasing quantity of ordered graphite is observed (Table 1 and Figure 6). Nevertheless, the pore 
Table 1. Summary of the $\mathbf{N}_{2}$ Physisorption Measurements

\begin{tabular}{lccc}
\multicolumn{1}{c}{ samples } & $S_{\mathrm{BET}}{ }^{b}, \mathrm{~m}^{2} / \mathrm{g}$ & $\mathrm{TPV}^{a, c}, \mathrm{~cm}^{3} / \mathrm{g}$ & $d_{\text {pore }}{ }^{a}, \mathrm{~nm}$ \\
SiO2@mSiO2 & 560 & 0.3 & 2.8 \\
HGScvd-800 & 2260 & 1.8 & 2.6 \\
HGScvd-900 & 2285 & 1.9 & 2.5 \\
HGScvd-1000 & 1060 & 1.3 & 2.6
\end{tabular}

${ }^{a}$ Determined via the $\mathrm{BJH}$ method from the adsorption branch (the desorption branch, which is normally recommended, might be influenced by capillary criticality). ${ }^{b}$ Surface area determined via the BET method between relative pressures of $p / p^{0}=0.05-0.3 .{ }^{c}$ For relative pressures at $0.95 p / p^{0}$ following the Gurvich rule.

diameter remains independent of the annealing temperature/ graphitization degree as illustrated by the pore size distribution. Figure 6 reveals that the heat treatment does not influence the templating process but the growth and/or final fraction of ordered carbon structures, as can be seen from the unaltered pore diameter, which is in agreement with the silica template.

To judge the reproducibility and scalability of the CVD process, a similar setup was built using a larger quartz tube (diameter NS45). To still allow sublimation of ferrocene into the furnace chamber, the temperature of the heating jacket was increased from 120 to $140{ }^{\circ} \mathrm{C}$. Under otherwise identical reaction conditions and furnace temperatures of $1000{ }^{\circ} \mathrm{C}$, more than $1.2 \mathrm{~g}$ of $\mathrm{HGS}$ was produced in one batch $\left(\mathrm{HGS}_{\mathrm{cvd}}{ }^{-}\right.$ 1000-NS45). A comparison of XRD, TGA, and DSC results is provided in Figure 7. A characterization by Raman spectroscopy and an overview of TEM micrographs are given in the Supporting Information (Figures S6 and S8).

The larger relative intensity of the reflexes at $26^{\circ}(002), 42^{\circ}$ (100), and $54^{\circ}(004)$ in the XRD pattern of $\mathrm{HGS}_{\mathrm{cvd}}-1000$ NS45 implies a higher degree of graphitization. The same can be inferred from TGA and DSC. While the sample synthesized using the smaller setup shows a distinct shoulder in the TGA curve, the same feature is not easily determined for $\mathrm{HGS}_{\mathrm{cvd}}{ }^{-}$ 1000-NS45, the weight loss curve is shifted to a slightly higher temperature as a whole. A rough estimation of the share of graphitic carbon by TGA is $>50$ wt $\%$. DSC shows a similar trend, suggesting that $\mathrm{HGS}_{\mathrm{cvd}}-1000-\mathrm{NS} 45$ contains a higher share of highly graphitic carbon.

Overall, the implementation of CVD synthesis in a different, larger setup proves the reproducibility and scalability of the process. The higher graphitization of the product in the larger setup, potentially caused by a different heating profile or a higher degree of pore filling of the template, is beneficial for the application in electrocatalysis and underlines the potential of this process for further improvement.

In order to investigate the potential benefit of the synthesized $\mathrm{HGS}_{\mathrm{cvd}}$, it was employed as a catalyst support for the ORR. Therefore, the $\mathrm{HGS}_{\mathrm{cvd}}-1000$ sample was loaded with 20 wt $\%$ of $\mathrm{Pt}$ nanoparticles by an incipient wetness impregnation method (Figure 8). $\mathrm{HGS}_{\mathrm{cvd}}-1000$ was selected

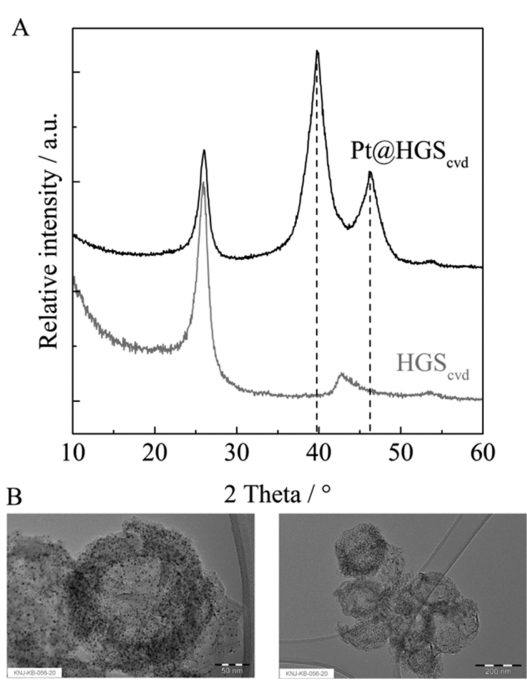

Figure 8. $\mathrm{HGS}_{\mathrm{CVD}} 1000$ loaded with $\mathrm{Pt}$ nanoparticles analyzed by XRD (A) and TEM (B).

for the electrochemical tests, as it was expected to offer higher conductivity and improved corrosion stability, thanks to the presence of the highly ordered graphite structures. ${ }^{43}$ The $\mathrm{Pt}$ average particle size of $3.1 \pm 0.5 \mathrm{~nm}$ determined by TEM (Figure S9) is similar to the size of the mesopores in $\mathrm{HGS}_{\mathrm{cvd}}$ measured via $\mathrm{N}_{2}$ physisorption, although pores below $10 \mathrm{~nm}$ are typically underestimated by $20-30 \%$ by the BJH method. ${ }^{41}$ The X-ray reflections at $39.67^{\circ}(111)$ and $45.96^{\circ}(200)$ can be clearly attributed to the impregnated $\mathrm{Pt}$ particles that are evenly distributed inside the mesopores of the support materials (Figure 8). The pronounced reflex broadening indicates the presence of small nanoparticles and the absence of large particles.

The electrochemical properties of $\mathrm{Pt} @ \mathrm{HGS}_{\mathrm{cvd}}-1000$ were evaluated via half-cell measurements, following two distinct accelerated degradation protocols (ADPs). For the first ADP, potentials present during typical load cycles were applied, in which the samples were exposed to potentials between 0.4 and
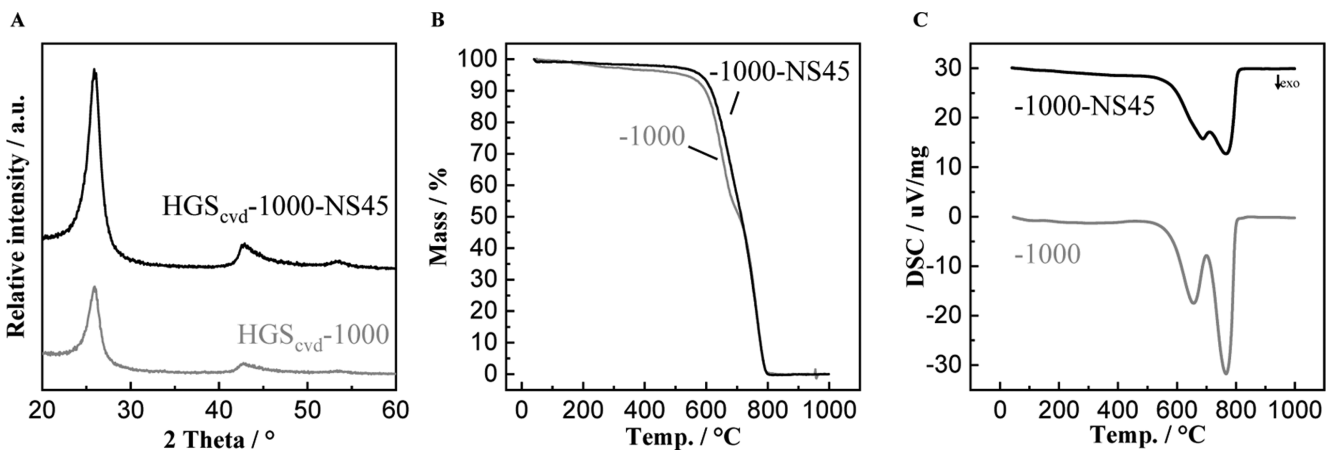

Figure 7. X-ray diffractogram (A), TGA (B), and DSC (C) of the $\mathrm{HGS}_{\text {cvd }}$ synthesized in two different setups. The DSC data is plotted with a respective $y$-axis offset of $30 \mu \mathrm{V} / \mathrm{mg}$. 

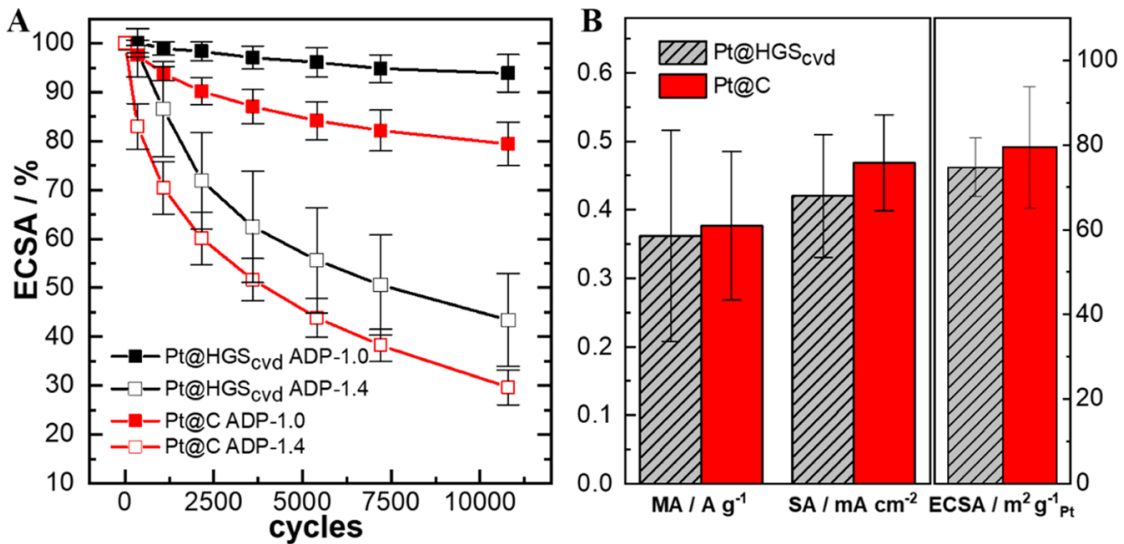

Figure 9. Comparison of the stability (A) and activity (B) of Pt@HGS $\mathrm{cvd}^{-1000}$ and Pt@C. The stability comparison was conducted following the $\mathrm{ADP}$ with an upper potential limit of 1.0 or $1.4 \mathrm{~V}_{\mathrm{RHE}}$. In (B), the MA, SA, and ECSA in the fresh state are shown.

$1.0 \mathrm{~V}_{\mathrm{RHE}}$ with a scan rate of $50 \mathrm{mV} / \mathrm{s}$ for 10,800 cycles $(\mathrm{ADP}$ 1.0). Higher potentials conceivably occurring during start-stop conditions were employed during the second accelerated degradation protocol (ADP-1.4), cycling between 0.4 and 1.4 $\mathrm{V}_{\mathrm{RHE}}$ (scan rate: $50 \mathrm{mV} / \mathrm{s} ; 10,800$ cycles). The respective degradation results, $\mathrm{SA}$, and $\mathrm{MA}$ of the catalysts are summarized in Figure 9.

In terms of activity, both Pt@HGS $\mathrm{cvd}^{-1000}$ and Pt supported on commercial high surface area carbons (Pt@C) show similar results, as expected, since both catalyst systems have similar particle sizes. In terms of stability, Pt@HGS $\mathrm{cvd}^{-1000}$ offer superior performance in direct comparison to $\mathrm{Pt} @ \mathrm{C}$, following the employed degradation protocols. For both ADP-1.0 and ADP-1.4, the loss in ECSA is significantly more pronounced for Pt@C compared to Pt@HGS $\mathrm{Hd}_{\mathrm{cr}}-1000$. The increased stability of Pt@HGS is consistent with previous reports by our group and was directly attributed to the confinement of the platinum nanoparticles in the pores of the HGS. This confinement suppresses the degradation of the nanoparticles by agglomeration and/or coalescence. ${ }^{10,11,17,18}$ The electrochemical analysis in the current work (Figure 9) verifies this improved electrochemical stability for Pt@HGS $\mathrm{cvd}^{-1000}$. The particular suitability of HGS as a support material for fuel cell catalysts therefore also applies to the material produced by CVD.

\section{CONCLUSIONS}

In summary, the successful synthesis of mesoporous hollow graphitic spheres $\left(\mathrm{HGS}_{\mathrm{cvd}}\right)$ via CVD has been demonstrated. The fraction of highly ordered graphite could be adjusted by variation of the annealing temperature. Shares of graphitic carbon of $>50$ wt $\%$ were obtained, employing ferrocene for the CVD and subsequent annealing at $1000{ }^{\circ} \mathrm{C}$. Thanks to the organometallic precursor, both the selective deposition of carbon and iron is achieved, where iron acts as a graphitization catalyst during the subsequent annealing step. The growth of the highly ordered graphite structures causes partial restructuring of the templated porous carbon network, reducing the surface area and the total pore volume as a result of graphitization.

The benefits of the porous network were revealed by the enhanced stability against electrochemical degradation in direct comparison to commercial catalysts, in which $\mathrm{Pt}$ is deposited on high surface area carbon materials.
Thanks to the CVD of ferrocene, the synthesis of HGS is possible without the need of a multi-step nanocasting process, reducing synthesis complexity and offering synthesis scalability as shown using the larger setup that yielded HGS with an even higher degree of graphitization.

\section{ASSOCIATED CONTENT}

\section{Supporting Information}

The Supporting Information is available free of charge at https://pubs.acs.org/doi/10.1021/acsaem.1c00643.

TEM micrographs of the composite after CVD; $\mathrm{N}_{2}$ physisorption data of the template before and after CVD; TGA of the composite before and after annealing at $800{ }^{\circ} \mathrm{C}$ for $4 \mathrm{~h}$; TEM micrographs of $\mathrm{HGS}_{\mathrm{cvd}}-700$ before and after the leaching procedure; Raman spectroscopy data; TEM micrographs of $\mathrm{HGS}_{\mathrm{cyd}}-\mathrm{NS} 45$; Platinum particle size distribution of the Pt@HGScvd1000 sample (PDF)

\section{AUTHOR INFORMATION}

\section{Corresponding Author}

F. Schüth - Department of Heterogeneous Catalysis, MaxPlanck-Institut für Kohlenforschung, 45470 Mülheim an der Ruhr, Germany; Email: schueth@kofo.mpg.de

\section{Authors}

J. Knossalla - Department of Heterogeneous Catalysis, MaxPlanck-Institut für Kohlenforschung, 45470 Mülheim an der Ruhr, Germany

J. Mielby - Centre for Catalysis and Sustainable Chemistry, Department of Chemistry, Technical University of Denmark, DK-2800 Kgs. Lyngby, Denmark; 이이.orcid.org/0000-00016588-2495

D. Göhl - Department of Interface Chemistry and Surface Engineering, Max-Planck-Institut für Eisenforschung GmbH, 40237 Düsseldorf, Germany; Department of Technical Chemistry, Technical University Darmstadt, 64287 Darmstadt, Germany

F. R. Wang - Department of Chemical Engineering, University College London, London WC1E 7JE, U.K.; 이이. orcid.org/ 0000-0002-2475-606X

D. Jalalpoor - Department of Heterogeneous Catalysis, MaxPlanck-Institut für Kohlenforschung, 45470 Mülheim an der Ruhr, Germany 
A. Hopf - Department of Heterogeneous Catalysis, MaxPlanck-Institut für Kohlenforschung, 45470 Mülheim an der Ruhr, Germany; (1) orcid.org/0000-0002-9424-3374

K. J. J. Mayrhofer - Department of Interface Chemistry and Surface Engineering, Max-Planck-Institut für Eisenforschung GmbH, 40237 Düsseldorf, Germany; Forschungszentrum Jülich GmbH, Helmholtz Institute Erlangen-Nürnberg for Renewable Energy (IEK-11), 91058 Erlangen, Germany; (1) orcid.org/0000-0002-4248-0431

M. Ledendecker - Department of Interface Chemistry and Surface Engineering, Max-Planck-Institut für Eisenforschung $\mathrm{GmbH}, 40237$ Düsseldorf, Germany; Department of Technical Chemistry, Technical University Darmstadt, 64287 Darmstadt, Germany

Complete contact information is available at: https://pubs.acs.org/10.1021/acsaem.1c00643

\section{Notes}

The authors declare no competing financial interest.

\section{ACKNOWLEDGMENTS}

D.J. and A.H. acknowledge the support of the IMPRS-SurMat doctoral program. Additionally, we thank Ann-Christin Swertz and Bernd Spliethoff for their help with the electron microscopy. This research was funded by the Federal Ministry for Economic Affairs and Energy (BMWi) of Germany in the framework of PtTM@HGS (project number 03ET6080A).

\section{REFERENCES}

(1) Seh, Z. W.; Kibsgaard, J.; Dickens, C. F.; Chorkendorff, I.; Nørskov, J. K.; Jaramillo, T. F. Combining theory and experiment in electrocatalysis: Insights into materials design. Science 2017, 355, 6321.

(2) Stamenkovic, V. R.; Strmcnik, D.; Lopes, P. P.; Markovic, N. M. Energy and fuels from electrochemical interfaces. Nat. Mater. 2017, $16,57-69$.

(3) Gasteiger, H. A.; Kocha, S. S.; Sompalli, B.; Wagner, F. T. Activity benchmarks and requirements for $\mathrm{Pt}, \mathrm{Pt}$-alloy, and non-Pt oxygen reduction catalysts for PEMFCs. Appl. Catal., B 2005, 56, 935 .

(4) Debe, M. K. Electrocatalyst approaches and challenges for automotive fuel cells. Nature 2012, 486, 43-51.

(5) Rabis, A.; Rodriguez, P.; Schmidt, T. J. Electrocatalysis for Polymer Electrolyte Fuel Cells: Recent Achievements and Future Challenges. ACS Catal. 2012, 2, 864-890.

(6) Gasteiger, H. A.; Marković, N. M. Just a Dream-or Future Reality? Science 2009, 324, 48-49.

(7) Mayrhofer, K. J. J.; Ashton, S. J.; Meier, J. C.; Wiberg, G. K. H.; Hanzlik, M.; Arenz, M. Non-destructive transmission electron microscopy study of catalyst degradation under electrochemical treatment. J. Power Sources 2008, 185, 734-739.

(8) Mayrhofer, K. J. J.; Meier, J. C.; Ashton, S. J.; Wiberg, G. K. H.; Kraus, F.; Hanzlik, M.; Arenz, M. Fuel cell catalyst degradation on the nanoscale. Electrochem. Commun. 2008, 10, 1144-1147.

(9) Meier, J. C.; Galeano, C.; Katsounaros, I.; Topalov, A. A.; Kostka, A.; Schüth, F.; Mayrhofer, K. J. J. Degradation Mechanisms of $\mathrm{Pt} / \mathrm{C}$ Fuel Cell Catalysts under Simulated Start-Stop Conditions. ACS Catal. 2012, 2, 832-843.

(10) Meier, J. C.; Katsounaros, I.; Galeano, C.; Bongard, H. J.; Topalov, A. A.; Kostka, A.; Karschin, A.; Schüth, F.; Mayrhofer, K. J. J. Stability investigations of electrocatalysts on the nanoscale. Energy Environ. Sci. 2012, 5, 9319-9330.

(11) Meier, J. C.; Galeano, C.; Katsounaros, I.; Witte, J.; Bongard, H. J.; Topalov, A. A.; Baldizzone, C.; Mezzavilla, S.; Schüth, F.; Mayrhofer, K. J. J. Design criteria for stable Pt/C fuel cell catalysts. Beilstein J. Nanotechnol. 2014, 5, 44-67.
(12) Baldizzone, C.; Mezzavilla, S.; Carvalho, H. W. P.; Meier, J. C.; Schuppert, A. K.; Heggen, M.; Galeano, C.; Grunwaldt, J.-D.; Schüth, F.; Mayrhofer, K. J. J. Confined-Space Alloying of Nanoparticles for the Synthesis of Efficient PtNi Fuel-Cell Catalysts. Angew. Chem., Int. Ed. 2014, 53, 14250-14254.

(13) Lu, A.-H.; Schüth, F. Nanocasting: A versatile strategy for creating nanostructured porous materials. Adv. Mater. 2006, 18, 1793-1805.

(14) Lou, X. W.; Archer, L. A.; Yang, Z. Hollow Micro-/ Nanostructures: Synthesis and Applications. Adv. Mater. 2008, 20, 3987-4019.

(15) Büchel, G.; Unger, K. K.; Matsumoto, A.; Tsutsumi, K. A Novel Pathway for Synthesis of Submicrometer-Size Solid Core/Mesoporous Shell Spheres. Adv. Mater. 1998, 10, 1036-1038.

(16) Knossalla, J.; Jalalpoor, D.; Schüth, F. Hands-on Guide to the Synthesis of Mesoporous Hollow Graphitic Spheres and Core-Shell Materials. Chem. Mater. 2017, 29, 7062-7072.

(17) Galeano, C.; Meier, J. C.; Peinecke, V.; Bongard, H.; Katsounaros, I.; Topalov, A. A.; Lu, A.; Mayrhofer, K. J. J.; Schüth, F. Toward Highly Stable Electrocatalysts via Nanoparticle Pore Confinement. J. Am. Chem. Soc. 2012, 134, 20457-20465.

(18) Pizzutilo, E.; Knossalla, J.; Geiger, S.; Grote, J. P.; Polymeros, G.; Baldizzone, C.; Mezzavilla, S.; Ledendecker, M.; Mingers, A.; Cherevko, S.; Schuth, F.; Mayrhofer, K. J. J. The Space Confinement Approach Using Hollow Graphitic Spheres to Unveil Activity and Stability of Pt-Co Nanocatalysts for PEMFC. Adv. Energy Mater. 2017, 7, 1700835.

(19) Knossalla, J.; Paciok, P.; Göhl, D.; Jalalpoor, D.; Pizzutilo, E.; Mingers, A. M.; Heggen, M.; Dunin-Borkowski, R. E.; Mayrhofer, K. J. J.; Schüth, F.; Ledendecker, M. Shape-Controlled Nanoparticles in Pore-Confined Space. J. Am. Chem. Soc. 2018, 140, 15684-15689.

(20) Huczko, A. Template-based synthesis of nanomaterials. Appl. Phys. A: Mater. Sci. Process. 2000, 70, 365-376.

(21) Kyotani, T.; Tsai, L.-f.; Tomita, A. Formation of Ultrafine Carbon Tubes by Using an Anodic Aluminum Oxide Film as a Template. Chem. Mater. 1995, 7, 1427-1428.

(22) Che, G.; Lakshmi, B. B.; Martin, C. R.; Fisher, E. R.; Ruoff, R. S. Chemical Vapor Deposition Based Synthesis of Carbon Nanotubes and Nanofibers Using a Template Method. Chem. Mater. 1998, 10, 260-267.

(23) Che, G.; Lakshmi, B. B.; Fisher, E. R.; Martin, C. R. Carbon nanotubule membranes for electrochemical energy storage and production. Nature 1998, 393, 346-349.

(24) Li, Y.-L.; Kinloch, I. A.; Windle, A. H. Direct Spinning of Carbon Nanotube Fibers from Chemical Vapor Deposition Synthesis. Science 2004, 304, 276-278.

(25) Kawabuchi, Y.; Kishino, M.; Kawano, S.; Whitehurst, D. D.; Mochida, I. Carbon Deposition from Benzene and Cyclohexane onto Active Carbon Fiber To Control Its Pore Size. Langmuir 1996, 12, $4281-4285$

(26) Li, W. Z.; Xie, S. S.; Qian, L. X.; Chang, B. H.; Zou, B. S.; Zhou, W. Y.; Zhao, R. A.; Wang, G. Large-Scale Synthesis of Aligned Carbon Nanotubes. Science 1996, 274, 1701-1703.

(27) Hüttinger, K. J. CVD in Hot Wall Reactors-The Interaction Between Homogeneous Gas-Phase and Heterogeneous Surface Reactions. Chem. Vap. Deposition 1998, 4, 151-158.

(28) Hoshikawa, Y.; Castro-Muñiz, A.; Komiyama, H.; Ishii, T.; Yokoyama, T.; Nanbu, H.; Kyotani, T. Remarkable enhancement of pyrolytic carbon deposition on ordered mesoporous silicas by their trimethylsilylation. Carbon 2014, 67, 156-167.

(29) Hu, Z. D.; Hu, Y. F.; Chen, Q.; Duan, X. F.; Peng, L.-M. Synthesis and Characterizations of Amorphous Carbon Nanotubes by Pyrolysis of Ferrocene Confined within AAM Templates. J. Phys. Chem. B 2006, 110, 8263-8267.

(30) Lei, Z.; Bai, S.; Xiao, Y.; Dang, L.; An, L.; Zhang, G.; Xu, Q. CMK-5 Mesoporous Carbon Synthesized via Chemical Vapor Deposition of Ferrocene as Catalyst Support for Methanol Oxidation. J. Phys. Chem. C 2008, 112, 722-731. 
(31) Schlögl, R. Carbons. Handbook of Heterogeneous Catalysis; Wiley-VCH Verlag GmbH \& Co. KGaA, 2008.

(32) Tada, M.; Iwasawa, Y. Supported Catalysts from Chemical Vapor Deposition and Related Techniques. Handbook of Heterogeneous Catalysis; Wiley-VCH Verlag GmbH \& Co. KGaA, 2008.

(33) Lei, Z.; Chen, Z.; Zhao, X. S. Growth of Polyaniline on Hollow Carbon Spheres for Enhancing Electrocapacitance. J. Phys. Chem. C 2010, 114, 19867-19874.

(34) Lei, Z.; Christov, N.; Zhang, L. L.; Zhao, X. S. Mesoporous carbon nanospheres with an excellent electrocapacitive performance. J. Mater. Chem. 2011, 21, 2274-2281.

(35) Lei, Z.; Zhang, J.; Zhao, X. S. Ultrathin $\mathrm{MnO} 2$ nanofibers grown on graphitic carbon spheres as high-performance asymmetric supercapacitor electrodes. J. Mater. Chem. 2012, 22, 153-160.

(36) Xu, R.; Kang, L.; Knossalla, J.; Mielby, J.; Wang, Q.; Wang, B.; Feng, J.; He, G.; Qin, Y.; Xie, J.; Swertz, A. C.; He, Q.; Kegnæs, S.; Brett, D. J. L.; Schüth, F.; Wang, F. R. Nanoporous Carbon: LiquidFree Synthesis and Geometry-Dependent Catalytic Performance. ACS Nano 2019, 13, 2463-2472.

(37) Zhang, Z. J.; Wei, B. Q.; Ramanath, G.; Ajayan, P. M. Substratesite selective growth of aligned carbon nanotubes. Appl. Phys. Lett. 2000, 77, 3764-3766.

(38) Feng, X.; Chee, S. W.; Sharma, R.; Liu, K.; Xie, X.; Li, Q.; Fan, S.; Jiang, K. In Situ TEM observation of the gasification and growth of carbon nanotubes using iron catalysts. Nano Res. 2011, 4, 767-779.

(39) Jourdain, V.; Bichara, C. Current understanding of the growth of carbon nanotubes in catalytic chemical vapour deposition. Carbon 2013, 58, 2-39.

(40) Helveg, S.; López-Cartes, C.; Sehested, J.; Hansen, P. L.; Clausen, B. S.; Rostrup-Nielsen, J. R.; Abild-Pedersen, F.; Nørskov, J. $\mathrm{K}$. Atomic-scale imaging of carbon nanofibre growth. Nature 2004, $427,426-429$.

(41) Thommes, M.; Kaneko, K.; Neimark, A. V.; Olivier, J. P.; Rodriguez-Reinoso, F.; Rouquerol, J.; Sing, K. S. Physisorption of gases, with special reference to the evaluation of surface area and pore size distribution (IUPAC Technical Report). Pure Appl. Chem. 2015, 87, 1051-1069.

(42) Käärik, M.; Arulepp, M.; Karelson, M.; Leis, J. The effect of graphitization catalyst on the structure and porosity of $\mathrm{SiC}$ derived carbons. Carbon 2008, 46, 1579-1587.

(43) Polymeros, G.; Baldizzone, C.; Geiger, S.; Grote, J. P.; Knossalla, J.; Mezzavilla, S.; Keeley, G. P.; Cherevko, S.; Zeradjanin, A. R.; Schüth, F.; Mayrhofer, K. J. J. High temperature stability study of carbon supported high surface area catalysts-Expanding the boundaries of ex-situ diagnostics. Electrochim. Acta 2016, 211, 744753. 